\title{
Air pollution and mortality in a large, representative U.S. cohort: multiple- pollutant analyses, and spatial and temporal decompositions
}

Jacob S. Lefler ${ }^{1 *}$ D, Joshua D. Higbee ${ }^{2}$, Richard T. Burnett ${ }^{3}$, Majid Ezzati ${ }^{4}$, Nathan C. Coleman ${ }^{5}$, Dalton D. Mann ${ }^{5}$, Julian D. Marshall, ${ }^{6}$ Matthew Bechle ${ }^{6}$, Yuzhou Wang ${ }^{6}$, Allen L. Robinson ${ }^{7}$ and C. Arden Pope $1 I^{5}$

\begin{abstract}
Background: Cohort studies have documented associations between fine particulate matter air pollution ( $\left.\mathrm{PM}_{2.5}\right)$ and mortality risk. However, there remains uncertainty regarding the contribution of co-pollutants and the stability of pollution-mortality associations in models that include multiple air pollutants. Furthermore, it is unclear whether the $\mathrm{PM}_{2.5}$-mortality relationship varies spatially, when exposures are decomposed according to scale of spatial variability, or temporally, when effect estimates are allowed to change between years.
\end{abstract}

Methods: A cohort of 635,539 individuals was compiled using public National Health Interview Survey (NHIS) data from 1987 to 2014 and linked with mortality follow-up through 2015. Modelled air pollution exposure estimates for $\mathrm{PM}_{2.5}$, other criteria air pollutants, and spatial decompositions $(<1 \mathrm{~km}, 1-10 \mathrm{~km}, 10-100 \mathrm{~km},>100 \mathrm{~km})$ of $\mathrm{PM}_{2.5}$ were assigned at the census-tract level. The NHIS samples were also divided into yearly cohorts for temporallydecomposed analyses. Cox proportional hazards models were used to estimate hazard ratios (HRs) and 95\% confidence intervals $(\mathrm{Cls})$ in regression models that included up to six criteria pollutants; four spatial decompositions of $\mathrm{PM}_{2.5}$; and two- and five-year lagged mean $\mathrm{PM}_{2.5}$ exposures in the temporally-decomposed cohorts. Meta-analytic fixed-effect estimates were calculated using results from temporally-decomposed analyses and compared with time-independent results using 17- and 28-year exposure windows.

Results: In multiple-pollutant analyses, $\mathrm{PM}_{2.5}$ demonstrated the most robust pollutant-mortality association. Coarse fraction particulate matter $\left(\mathrm{PM}_{2.5-10}\right)$ and sulfur dioxide $\left(\mathrm{SO}_{2}\right)$ were also associated with excess mortality risk. The $\mathrm{PM}_{2.5}$-mortality association was observed across all four spatial scales of $\mathrm{PM}_{2.5}$, with higher but less precisely estimated HRs observed for local $(<1 \mathrm{~km})$ and neighborhood $(1-10 \mathrm{~km})$ variations. In temporally-decomposed analyses, the $\mathrm{PM}_{2.5}$-mortality HRs were stable across yearly cohorts. The meta-analytic HR using two-year lagged $\mathrm{PM}_{2.5}$ equaled $1.10(95 \% \mathrm{Cl} 1.07,1.13)$ per $10 \mu \mathrm{g} / \mathrm{m}^{3}$. Comparable results were observed in time-independent analyses using a 17-year ( $\mathrm{HR} 1.13, \mathrm{Cl} 1.09,1.16)$ or 28-year (HR 1.09, Cl 1.07, 1.12) exposure window.

Conclusions: Long-term exposures to $\mathrm{PM}_{2.5}, \mathrm{PM}_{2.5-10}$, and $\mathrm{SO}_{2}$ were associated with increased risk of all-cause and cardiopulmonary mortality. Each spatial decomposition of $\mathrm{PM}_{2.5}$ was associated with mortality risk, and $\mathrm{PM}_{2.5}$ mortality associations were consistent over time.

Keywords: Air pollution, Particulate matter, Sulfur dioxide, Mortality, Cardiopulmonary disease

\footnotetext{
* Correspondence: jacob_lefler@berkeley.edu

${ }^{1}$ Department of Agricultural and Resource Economics, University of California,

Berkeley, CA 94720, USA

Full list of author information is available at the end of the article
}

(c) The Author(s). 2019 Open Access This article is distributed under the terms of the Creative Commons Attribution 4.0 International License (http://creativecommons.org/licenses/by/4.0/), which permits unrestricted use, distribution, and reproduction in any medium, provided you give appropriate credit to the original author(s) and the source, provide a link to the Creative Commons license, and indicate if changes were made. The Creative Commons Public Domain Dedication waiver (http://creativecommons.org/publicdomain/zero/1.0/) applies to the data made available in this article, unless otherwise stated. 


\section{Background}

Numerous studies have documented associations between long-term exposure to fine particulate matter air pollution $\left(\mathrm{PM}_{2.5}\right.$, particles $<2.5 \mu \mathrm{m}$ in aerodynamic diameter) and risk of mortality. Notable cohort studies have indicated that elevated $\mathrm{PM}_{2.5}$ exposures are associated with increased risks of all-cause and cardiopulmonary mortality [1-25]. Several studies have estimated the association between $\mathrm{PM}_{2.5}$ and mortality while controlling for exposures to one or more co-pollutants, such as ozone $\left(\mathrm{O}_{3}\right)$, nitrogen dioxide $\left(\mathrm{NO}_{2}\right)$, and sulfur dioxide $\left(\mathrm{SO}_{2}\right)[4,5,13,20]$. There remains a need for further multiple-pollutant analyses that control for other common air pollutants, including coarse fraction particulate matter $\left(\mathrm{PM}_{2.5-10}\right.$, particles $2.5-10 \mu \mathrm{m}$ in aerodynamic diameter) and carbon monoxide (CO).

Related to multiple-pollutant analyses are models that examine constituents of $\mathrm{PM}_{2.5}$ rather than aggregated $\mathrm{PM}_{2.5}$ treated as a single pollutant. The composition and toxicity of $\mathrm{PM}_{2.5}$ can vary substantially based on when and where it is sampled and the distance from the pollution source [26, 27]. Exposures that occur near a pollution source may include a larger fraction of primary combustion products (black carbon and primary organic aerosol) and other local sources (industrial and road dust). Alternatively, exposure may occur farther from the source, allowing a larger fraction of aged, agglomerated, and secondary particulate matter (sulfates, nitrates, and secondary organic aerosol). Are there differences in the $\mathrm{PM}_{2.5}$-mortality associations across spatial decompositions of $\mathrm{PM}_{2.5}$ pollution?

The composition of $\mathrm{PM}_{2.5}$ not only varies spatially, but may also vary temporally as sources of pollution change. Furthermore, ambient pollution levels change over time, and observed health effects of $\mathrm{PM}_{2.5}$ likely depend on the window of exposure assigned to individuals in the cohort. Therefore, an important question is, are there differences in observed $\mathrm{PM}_{2.5}$-mortality associations across time or for different windows of $\mathrm{PM}_{2.5}$ exposure?

This study uses a large, well-documented, and representative cohort of the U.S. [25] to pursue three primary objectives. First, investigate pollution-mortality associations with models that include multiple air pollutants. Second, explore differences in $\mathrm{PM}_{2.5}$-mortality associations across spatially-decomposed $\mathrm{PM}_{2.5}$ as an evaluation of whether the impact of $\mathrm{PM}_{2.5}$ depends on distance from pollution source. Third, estimate $\mathrm{PM}_{2.5}$-mortality associations in temporally-decomposed cohorts, allowing effect estimates to vary across time and for different choices of exposure window.

\section{Methods}

\section{Study population}

The cohort for this study was constructed using publicly-available National Health Interview Survey
(NHIS) data from 1987 to 2014, linked with restricteduse geographic information and mortality follow-up through 2015. The sample was limited to NHIS respondents aged 18-84 at the time of survey for whom information was available regarding age, sex, raceethnicity, income, education, marital status, smoking status, BMI, census tract, ambient air pollution, survey date, mortality status at the end of 2015, and date of death (if deceased at the end of 2015).

The NHIS is a household survey administered annually by the National Center for Health Statistics (NCHS) and designed to be representative of the civilian noninstitutionalized U.S. population [28]. Survey data were linked with the National Death Index for mortality follow-up through 2015 [29]. The construction of this cohort has been described in a previous study [25], where it was referred to as a "subcohort" of a larger NHIS cohort. This cohort, rather than the larger "full cohort" of the prior study, was chosen for the present analysis because it included information for smoking status and BMI. The NHIS design was altered periodically over the sample period, so some variables required harmonization. Data linkage was performed with permission and assistance from the NCHS. Further details on construction, harmonization, and data linkage for the NHIS cohort are documented elsewhere [25].

\section{Air pollution data}

Air pollution exposures were assigned to individuals based on their census tract of residence at the time of survey, using year-2000 Census tracts for individuals surveyed from 1987 to 2010 and year-2010 Census tracts for individuals surveyed from 2011 to 2014. Annualaverage estimates of ambient air pollution were calculated for criteria pollutants $\left(\mathrm{PM}_{2.5}, \mathrm{PM}_{10}, \mathrm{SO}_{2}, \mathrm{NO}_{2}, \mathrm{O}_{3}\right.$, and $\mathrm{CO}$ ) using estimates from the v1 empirical models of Kim et al., 2018 [30], available at www.caces.us. These models employed regulatory monitoring and land-use data, and pollution estimates were calculated starting with the first year for which nationwide monitoring data were available for that pollutant (1979 for $\mathrm{SO}_{2}, \mathrm{NO}_{2}$, and $\mathrm{O}_{3} ; 1988$ for $\mathrm{PM}_{10} ; 1990$ for $\mathrm{CO}$; and 1999 for $\mathrm{PM}_{2.5}$ ). In the case of $\mathrm{O}_{3}$, annual values are the mean for May through September of the daily maximum eighthour moving average. $\mathrm{O}_{3}$ monitoring is not widely and routinely conducted from October through April since these months typically experience very low $\mathrm{O}_{3}$ concentrations. Estimates for each pollutant-year through 2015 were generated at the census-block level using year-2010 Census block centroids. Tract-level estimates for year2000 Census tracts and year-2010 Census tracts were estimated by mapping year-2010 Census blocks to census tracts and then calculating a population-weighted average of the census blocks within a census tract. $\mathrm{PM}_{2.5}$ 
exposures prior to 1999 were estimated by multiplying a census tract's $\mathrm{PM}_{10}$ value with the census tract's mean $\mathrm{PM}_{2.5}: \mathrm{PM}_{10}$ ratio from 1999 to 2003, as explained elsewhere [25]. Values for $\mathrm{PM}_{2.5-10}$ were calculated by subtracting $\mathrm{PM}_{2.5}$ from $\mathrm{PM}_{10}$.

In addition, spatially-decomposed $\mathrm{PM}_{2.5}$ data were generated following an approach described elsewhere [26]. Briefly, a census block's total ambient $\mathrm{PM}_{2.5}$ was decomposed into four components, depending on the spatial variance in $\mathrm{PM}_{2.5}$ surrounding the census block. Estimating spatial decompositions involved finding and subtracting the minimum $\mathrm{PM}_{2.5}$ values within circular buffers around each census block. First, the minimum $\mathrm{PM}_{2.5}$ for census block centroids within a $100 \mathrm{~km}$ radius of a given census block centroid was found, and this minimum was designated as regional $(>100 \mathrm{~km}) \mathrm{PM}_{2.5}$. After subtracting regional $\mathrm{PM}_{2.5}$, the minimum $\mathrm{PM}_{2.5}$ within a $10 \mathrm{~km}$ radius of the census block centroid was found, and this value was designated as mid-range $(10-100 \mathrm{~km}) \mathrm{PM}_{2.5}$. Next, the minimum value within $1 \mathrm{~km}$ of the block centroid was similarly used to calculate neighborhood (1-10 km) $\mathrm{PM}_{2.5}$ by subtracting regional and mid-range $\mathrm{PM}_{2.5}$. Finally, the residual $\mathrm{PM}_{2.5}$ that remained after subtracting regional, mid-range, and neighborhood $\mathrm{PM}_{2.5}$ was called local $(<1$ $\mathrm{km}) \mathrm{PM}_{2.5}$. The process was repeated for each year-2010 Census block and for each year from 2000 through 2015. Values for census tracts were calculated using populationweighted averages of year-2010 Census blocks.

\section{Statistical analyses}

Statistical analyses were performed at the NCHS Research Data Center in Hyattsville, MD, using SAS (version 9.3; SAS Institute). Survival analyses were performed for all-cause and cardiopulmonary mortality, with cardiopulmonary mortality defined as mortality due to cardiovascular disease (ICD-10 codes: I00-I09, I11, I13, I20-I51), cerebrovascular disease (I60-I69), chronic lower respiratory disease (J40-J47), and influenza or pneumonia (J09-J18). Mortality hazard ratios (HRs) and 95\% confidence intervals (CIs) were estimated using two versions of the Cox proportional hazards $(\mathrm{PH})$ model. The first PH model, referred to as the basic PH model, controlled for age, sex, and race-ethnicity by allowing each combination of age (in one-year increments), sex, and race-ethnicity (Hispanic, non-Hispanic black, nonHispanic white, other or unknown) its own baseline hazard function using the STRATA statement of the PHREG procedure in SAS. The second PH model, referred to as the complex $\mathrm{PH}$ model, controlled for age group (18-24 years and subsequent five-year age groups), sex, and race-ethnicity by including an indicator variable for each interaction of age group, sex, and raceethnicity. The complex PH model was estimated using the SURVEYPHREG procedure in SAS, adjusting for the
NHIS complex survey design, using reported survey stratum, primary sampling unit, and sample weight from mortality follow-up files [28].

Both PH models controlled for covariates by including indicator variables for each value of marital status (never married, married, separated, divorced, widowed), inflation-adjusted household income $(\$ 0-35,000 ; \$ 35$, 000-50,000; \$50,000-75,000; >\$75,000), education ( $<$ high school graduate, high school graduate, some college, college graduate, >college graduate), smoking status (current, former, never), BMI $(<20,20-25,25-30,30$ $35,>35)$, U.S. Census region, urban versus rural designation, and survey year. Survival time was the number of days between survey and death. For all-cause mortality, censored survival time was the number of days between survey and mortality follow-up (31 Dec 2015). In models that considered cardiopulmonary mortality, censored survival time was the number of days between survey and mortality follow-up, or the number of days between survey and non-cardiopulmonary mortality. Pollution values were included as continuous variables in the regressions.

In models using criteria pollutants $\left(\mathrm{PM}_{2.5}, \mathrm{PM}_{2.5-10}\right.$, $\mathrm{SO}_{2}, \mathrm{NO}_{2}, \mathrm{O}_{3}$, and $\mathrm{CO}$ ), regressions included one, two, or six pollutants, and were estimated for both all-cause and cardiopulmonary mortality. One- and two-pollutant regression models used the basic PH model. For sixpollutant regression models, both the basic and complex $\mathrm{PH}$ models were employed to examine whether results were sensitive to adjusting for the NHIS complex survey design. Basic PH models were also used to estimate the associations between spatial decompositions of $\mathrm{PM}_{2.5}$ and risk of all-cause and cardiopulmonary mortality. Regressions were performed for each of the four decompositions individually and for models that included all four decompositions.

For temporally-decomposed analyses, the NHIS cohort was decomposed into 24 yearly cohorts (1992-2015), beginning in 1992 to allow up to a five-year lagged pollution-exposure window. An individual in the NHIS cohort was included in a particular year's cohort if she was alive on 1 Jan and was surveyed by 31 Dec of that year. For example, the 1992 cohort included those surveyed before 1992 and alive on 1 Jan 1992. It also included those who were surveyed in 1992. For those who died in 1992, survival time was the number of days between 1 Jan 1992 and date of death (for individuals surveyed before 1992), or the number of days between survey date and date of death (for individuals surveyed in 1992). For those who did not die in 1992, censored survival time was the number of days between 1 Jan and 31 Dec (for individuals surveyed before 1992), or the number of days between survey date and 31 Dec (for individuals surveyed in 1992). Analogous cohorts were 
constructed for each year from 1993 to 2015. The construction of these yearly cohorts is illustrated in Additional file 1: Figure S1.

Complex PH regressions were performed for all-cause and cardiopulmonary mortality for each of the 24 temporally-decomposed cohorts. In each cohort, individuals were assigned a two-year (cohort year and previous year) and five-year (cohort year and four previous years) average of ambient $\mathrm{PM}_{2.5}$ using their census tract of residence at time of survey. In addition, age was adjusted to age in cohort year. Other covariates were not updated between cohorts. Meta-analytic fixed-effect estimates of the HR associated with a $10 \mu \mathrm{g} / \mathrm{m}^{3}$ increase in mean ambient $\mathrm{PM}_{2.5}$ were calculated for all-cause and cardiopulmonary mortality using estimates generated by the 24 yearly cohorts (Comprehensive Meta Analysis Ver. 3 Biostat Englewood, NJ).

\section{Results}

Table 1 presents summary statistics for the NHIS cohort. Table 2 provides summary statistics (mean, standard deviation, and interquartile range [IQR]) for the 17year (1999-2015) averages of the six criteria pollutants $\left(\mathrm{PM}_{2.5}, \mathrm{PM}_{2.5-10}, \mathrm{SO}_{2}, \mathrm{NO}_{2}, \mathrm{O}_{3}\right.$, and $\left.\mathrm{CO}\right)$ and correlation coefficients between pollutants, within the NHIS cohort. Criteria pollutants were generally positively correlated, with the exception of $\mathrm{PM}_{2.5-10}$ and $\mathrm{SO}_{2}$ (see Table 2). Figure 1 presents heat maps for the six criteria pollutants across census tracts in the contiguous U.S.

Figure 2 illustrates the HRs (and 95\% CIs) estimated in regression models with the six criteria pollutants, using one-, two-, and six-pollutant models. HRs and CIs in Fig. 2 are presented relative to each pollutant's IQR. Exposure to $\mathrm{PM}_{2.5}$ was consistently associated with increased risk of all-cause and cardiopulmonary mortality, and the $\mathrm{PM}_{2.5}$-mortality associations were statistically significant and insensitive to controlling for other pollutants. Exposures to $\mathrm{PM}_{2.5-10}$ and $\mathrm{SO}_{2}$ were also associated with increased mortality risk, including in sixpollutant models, but the associations were less robust. $\mathrm{NO}_{2}, \mathrm{O}_{3}$, and $\mathrm{CO}$ were not consistently linked with excess mortality risk. In models that controlled for $\mathrm{PM}_{2.5}$, exposures to $\mathrm{NO}_{2}$ were associated with reduced mortality risk. Furthermore, $\mathrm{O}_{3}$ was not associated with excess risk of all-cause mortality in six-pollutant models, and $\mathrm{O}_{3}$-mortality associations were marginally significant in six-pollutant cardiopulmonary regression models. Estimated HRs were not sensitive to using the complex $\mathrm{PH}$ regression model.

Because the IQR of $\mathrm{PM}_{2.5-10}\left(5.42 \mu \mathrm{g} / \mathrm{m}^{3}\right)$ is larger than the IQR of $\mathrm{PM}_{2.5}\left(3.12 \mu \mathrm{g} / \mathrm{m}^{3}\right)$, the pollution-mortality HRs associated with these two pollutants appear more similar in Fig. 2 than when scaled by $10 \mu \mathrm{g} / \mathrm{m}^{3}$. In the two-pollutant basic $\mathrm{PH}$ model with $\mathrm{PM}_{2.5}$ and $\mathrm{PM}_{2.5-10}$,
Table 1 Baseline unweighted characteristics of the NHIS cohort

\begin{tabular}{|c|c|}
\hline Variable & NHIS Cohort \\
\hline Total number in cohort & 635,539 \\
\hline Total Deaths & 106,385 \\
\hline Cardiopulmonary ${ }^{a}$ & 43,195 \\
\hline \multicolumn{2}{|l|}{ Sex } \\
\hline$\%$ Male & 44.54 \\
\hline$\%$ Female & 55.46 \\
\hline Age yrs. (mean) & 45.3 \\
\hline \multicolumn{2}{|l|}{ Race/Ethnicity } \\
\hline \% Non-Hispanic White & 67.51 \\
\hline$\%$ Hispanic & 14.08 \\
\hline \% Non-Hispanic Black & 14.01 \\
\hline$\%$ All other/unknown & 4.40 \\
\hline \multicolumn{2}{|c|}{ Income (inflation adjusted to 2015) } \\
\hline$\% \$ 0-35,000$ & 38.04 \\
\hline$\% \$ 35-50,000$ & 15.47 \\
\hline$\% \$ 50-75,000$ & 18.79 \\
\hline$\% \$ 75,000+$ & 27.71 \\
\hline \multicolumn{2}{|l|}{ Marital Status } \\
\hline$\%$ Married & 49.57 \\
\hline$\%$ Divorced & 14.06 \\
\hline$\%$ Separated & 3.59 \\
\hline$\%$ Never Married & 24.31 \\
\hline$\%$ Widowed & 8.47 \\
\hline \multicolumn{2}{|l|}{ Education } \\
\hline$\%<$ High School grad & 18.63 \\
\hline$\%$ High School grad & 30.37 \\
\hline$\%$ Some College & 27.10 \\
\hline$\%$ College grad & 15.03 \\
\hline$\%>$ College grad & 8.87 \\
\hline \multicolumn{2}{|l|}{ Urban/Rural } \\
\hline$\%$ Urban & 77.64 \\
\hline$\%$ Rural & 22.36 \\
\hline \multicolumn{2}{|l|}{ Census Region } \\
\hline$\%$ Northeast & 18.08 \\
\hline$\%$ Midwest & 23.71 \\
\hline$\%$ South & 35.74 \\
\hline$\%$ West & 22.46 \\
\hline \multicolumn{2}{|l|}{ BMI } \\
\hline$\%<20$ & 7.28 \\
\hline$\% 20-25$ & 36.37 \\
\hline$\%$ 25-30 & 33.80 \\
\hline \% 30-35 & 14.43 \\
\hline$\%>35$ & 8.12 \\
\hline Smoking & \\
\hline
\end{tabular}


Table 1 Baseline unweighted characteristics of the NHIS cohort (Continued)

\begin{tabular}{ll}
\hline Variable & NHIS Cohort \\
\hline$\%$ Never & 53.76 \\
$\%$ Current & 23.90 \\
$\%$ Former & 22.34 \\
\hline
\end{tabular}

${ }^{a}$ Cardiopulmonary mortality is based on International Statistical Classification of Diseases, Injuries, and Causes of Death, Tenth Revision (ICD-10) and includes: cardiovascular disease (100-109, I11, 113, 120-151), cerebrovascular disease (160-169), chronic lower respiratory disease (J40-J47), and influenza and pneumonia (J09-J18)

the all-cause mortality HR associated with a $10 \mu \mathrm{g} / \mathrm{m}^{3}$ increase in $\mathrm{PM}_{2.5}$ is 1.12 (95\% CI: $\left.1.09,1.15\right)$, whereas the $\mathrm{HR}$ associated with a $10 \mu \mathrm{g} / \mathrm{m}^{3}$ increase in $\mathrm{PM}_{2.5-10}$ is 1.02 $(1.00,1.04)$. Thus, when considered per $10 \mu \mathrm{g} / \mathrm{m}^{3}$, exposure to $\mathrm{PM}_{2.5}$ is associated with about six times greater excess risk than $\mathrm{PM}_{2.5-10}$.

Table 3 provides summary statistics and correlations for 16-year (2000-2015) averages of spatial decompositions of $\mathrm{PM}_{2.5}$ (local $\mathrm{PM}_{2.5},<1 \mathrm{~km}$; neighborhood $\mathrm{PM}_{2.5}$, 1-10 km; mid-range $\mathrm{PM}_{2.5}, 10-100 \mathrm{~km}$; regional $\mathrm{PM}_{2.5}$, $>100 \mathrm{~km}$ ), within the NHIS cohort. Although local, neighborhood, and mid-range $\mathrm{PM}_{2.5}$ are somewhat correlated, regional $\mathrm{PM}_{2.5}$ is mostly uncorrelated with local $\mathrm{PM}_{2.5}$ and negatively correlated with neighborhood and mid-range $\mathrm{PM}_{2.5}$ (see Table 3). Table 3 reports large differences in the means and IQRs of the spatial decompositions of $\mathrm{PM}_{2.5}$.

Fig. 3 presents estimated HRs for all-cause and cardiopulmonary mortality from models including spatiallydecomposed $\mathrm{PM}_{2.5}$. In the top panel, HRs are presented per $10 \mu \mathrm{g} / \mathrm{m}^{3}$ to assess the toxicity of spatial components of particulate matter. The same results are also presented as scaled by IQR (bottom panel) to account for differences in exposure variability across spatial decompositions of $\mathrm{PM}_{2.5}$. Regression results from models that included individual spatial decompositions were comparable to results from models that included all four spatial decompositions. Both types of model provide some evidence that local $\mathrm{PM}_{2.5}$ and neighborhood $\mathrm{PM}_{2.5}$ may be more toxic than mid-range and regional $\mathrm{PM}_{2.5}$.

Fig. 4 presents results from the temporally-decomposed analysis. HRs for all-cause and cardiopulmonary mortality associated with a $10 \mu \mathrm{g} / \mathrm{m}^{3}$ increase in two-year mean $\mathrm{PM}_{2.5}$ are presented from regressions performed on the 24 temporally-decomposed cohorts. These $\mathrm{PM}_{2.5}$-mortality associations were consistent across follow-up years. Although $\mathrm{PM}_{2.5}$-mortality associations were generally not statistically significant for individual cohort years, metaanalytic estimates of pooled results were statistically significant. HRs from fixed-effect meta-analyses of HRs from the 24 cohorts are also presented for two- and five-year mean $\mathrm{PM}_{2.5}$ and for all-cause and cardiopulmonary mortality. HRs associated with two-year and five-year mean $\mathrm{PM}_{2.5}$ were nearly identical. Also presented are HRs from time-independent analyses which used the entire NHIS cohort and 17-year (1999-2015) or 28-year (1988-2015) mean $\mathrm{PM}_{2.5}$. HRs from meta-analyses of temporallydecomposed regressions were greater than HRs associated with 28-year mean $\mathrm{PM}_{2.5}$ but less than HRs associated with 17-year mean $\mathrm{PM}_{2.5}$.

\section{Discussion}

This study advances our understanding of mortality risk associated with long-term exposure to $\mathrm{PM}_{2.5}$ in several ways. First, it illustrates that the $\mathrm{PM}_{2.5}$-mortality association within a large cohort is not highly sensitive to controlling for other air pollutants. Second, results from multiple-pollutant models report that, while mortality risk associated with $\mathrm{PM}_{2.5}$ exposure was the most prominent and robust result, exposures to elevated levels of $\mathrm{SO}_{2}$ and $\mathrm{PM}_{2.5-10}$ were also consistently linked to excess mortality risk. Third, regressions using spatiallydecomposed $\mathrm{PM}_{2.5}$ suggest that more spatially variable components $(<10 \mathrm{~km})$ of $\mathrm{PM}_{2.5}$ exposures may be more toxic. Fourth, mortality risk was significantly associated with all spatial decompositions of $\mathrm{PM}_{2.5}$, indicating that the $\mathrm{PM}_{2.5}$-mortality association within the U.S. is likely not the result of exclusively regional or local

Table 2 Correlations (Pearson's r) and summary statistics of criteria pollutants (1999-2015) in the NHIS cohort

\begin{tabular}{|c|c|c|c|c|c|c|c|c|c|}
\hline & $\mathrm{PM}_{2.5}$ & $\mathrm{PM}_{2.5-10}$ & $\mathrm{SO}_{2}$ & $\mathrm{NO}_{2}$ & $\mathrm{O}_{3}$ & $\mathrm{CO}$ & Mean & SD & $\mathrm{IQR}$ \\
\hline $\mathrm{PM}_{2.5}\left(10 \mu \mathrm{g} / \mathrm{m}^{3}\right)$ & & & & & & & 10.67 & 2.37 & 3.12 \\
\hline $\mathrm{PM}_{2.5-10}\left(10 \mu \mathrm{g} / \mathrm{m}^{3}\right)$ & 0.19 & & & & & & 9.77 & 4.51 & 5.42 \\
\hline $\mathrm{SO}_{2}(\mathrm{ppb})$ & 0.41 & -0.34 & & & & & 2.25 & 1.01 & 1.26 \\
\hline $\mathrm{NO}_{2}(\mathrm{ppb})$ & 0.56 & 0.44 & 0.37 & & & & 10.69 & 5.73 & 6.72 \\
\hline $\mathrm{O}_{3}(\mathrm{ppb})$ & 0.33 & 0.17 & 0.17 & 0.11 & & & 47.45 & 5.31 & 6.75 \\
\hline $\mathrm{CO}(\mathrm{ppm})$ & 0.42 & 0.56 & 0.17 & 0.90 & 0.04 & & 0.37 & 0.10 & 0.10 \\
\hline
\end{tabular}

Note: $\mathrm{PM}_{2.5}$, fine particulate matter (particles $<2.5 \mu \mathrm{m}$ in aerodynamic diameter); $\mathrm{PM}_{2.5-10}$, coarse fraction particulate matter (particles $2.5-10 \mu \mathrm{m}$ in aerodynamic diameter); $\mathrm{SO}_{2}$, sulfur dioxide; $\mathrm{NO}_{2}$, nitrogen dioxide; $\mathrm{O}_{3}$, ozone, mean for May-September of daily max of eight-hour moving average; $\mathrm{CO}$, carbon monoxide; $\mathrm{SD}$, standard deviation; IQR, interquartile range 


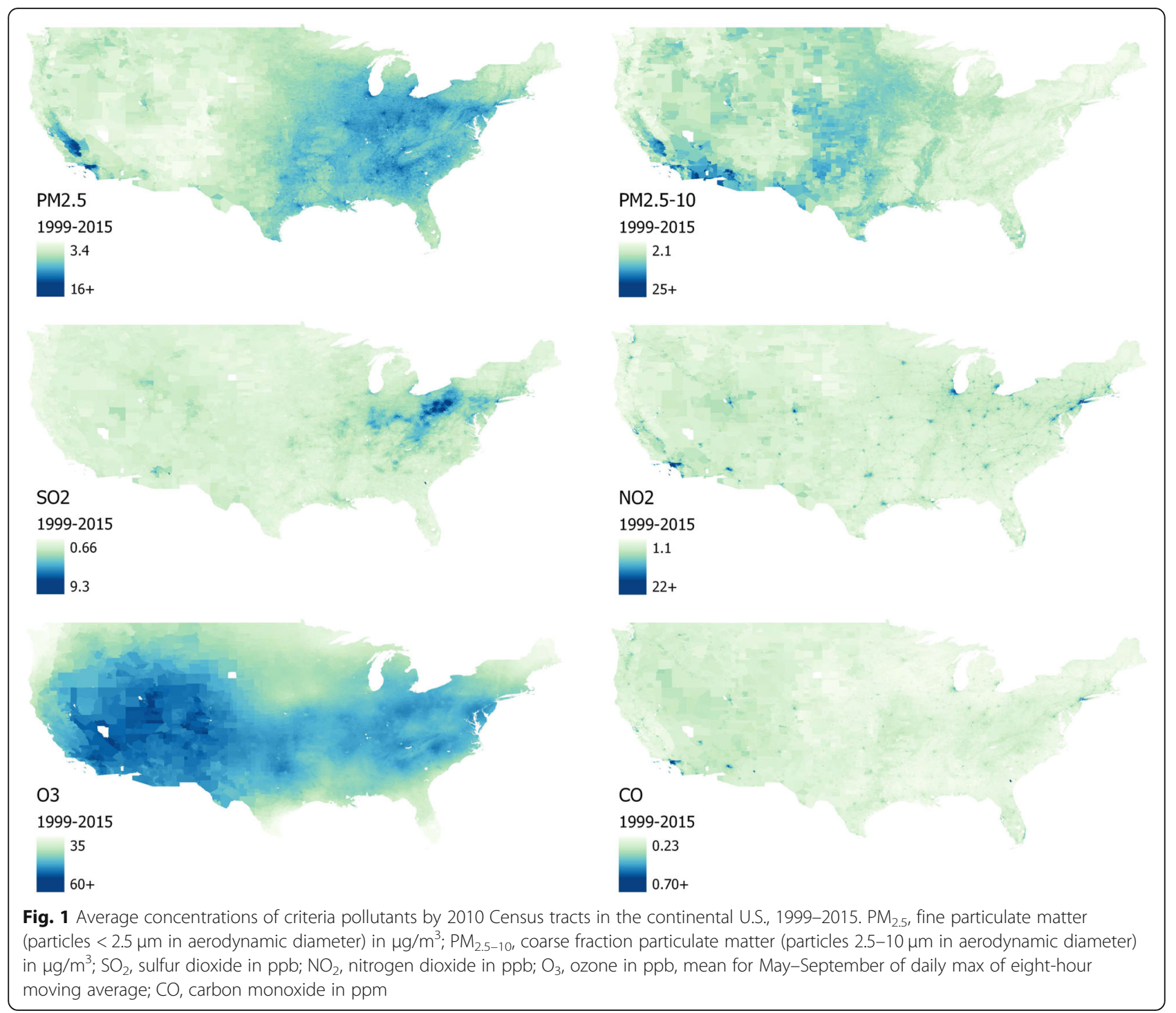

confounders. And fifth, the temporally-decomposed analysis indicates that $\mathrm{PM}_{2.5}$-mortality associations were largely consistent over time within the NHIS cohort, but provides incomplete evidence regarding the most relevant window of pollution exposure.

The robustness of the $\mathrm{PM}_{2.5}$-mortality association has been reported by various studies, including studies using two- or three-pollutant models $[4,5,13,20]$. Our results regarding risks associated with other air pollutants, however, were less congruent with existing literature. For example, this study found a relatively stable association between $\mathrm{PM}_{2.5-10}$ and mortality, which contrasts with the lack of consistent associations in similar cohort studies [31]. Similarly, previous studies examining the effect of long-term $\mathrm{O}_{3}$ exposures reported results that remained significant when controlling for $\mathrm{PM}_{2.5}$ and $\mathrm{NO}_{2}[4,13,20]$, while this study found that the association was stable except in six-pollutant models. The mortality association with $\mathrm{NO}_{2}$ was extremely sensitive to the inclusion of other pollutants, especially $\mathrm{PM}_{2.5}$. Ultimately, the clearest signals emerging from multiplepollutant regressions were that the $\mathrm{PM}_{2.5}$-mortality association was the most robust among these pollutants and that the mortality associations of other pollutants require further investigation.

The spatially-decomposed analyses are interesting because they provide insight into different components of $\mathrm{PM}_{2.5} \cdot \mathrm{PM}_{2.5}$ is largely comprised of regional and mid-range components which are presumably dominated by secondary material (sulfates, nitrates, and secondary organic aerosol). The neighborhood and local components contribute a relatively small fraction of the $\mathrm{PM}_{2.5}$ mass (6 and $17 \%$ respectively) but are presumably more influenced by local emissions and therefore comprised of combustion emissions (black carbon and primary organic aerosol) and other 


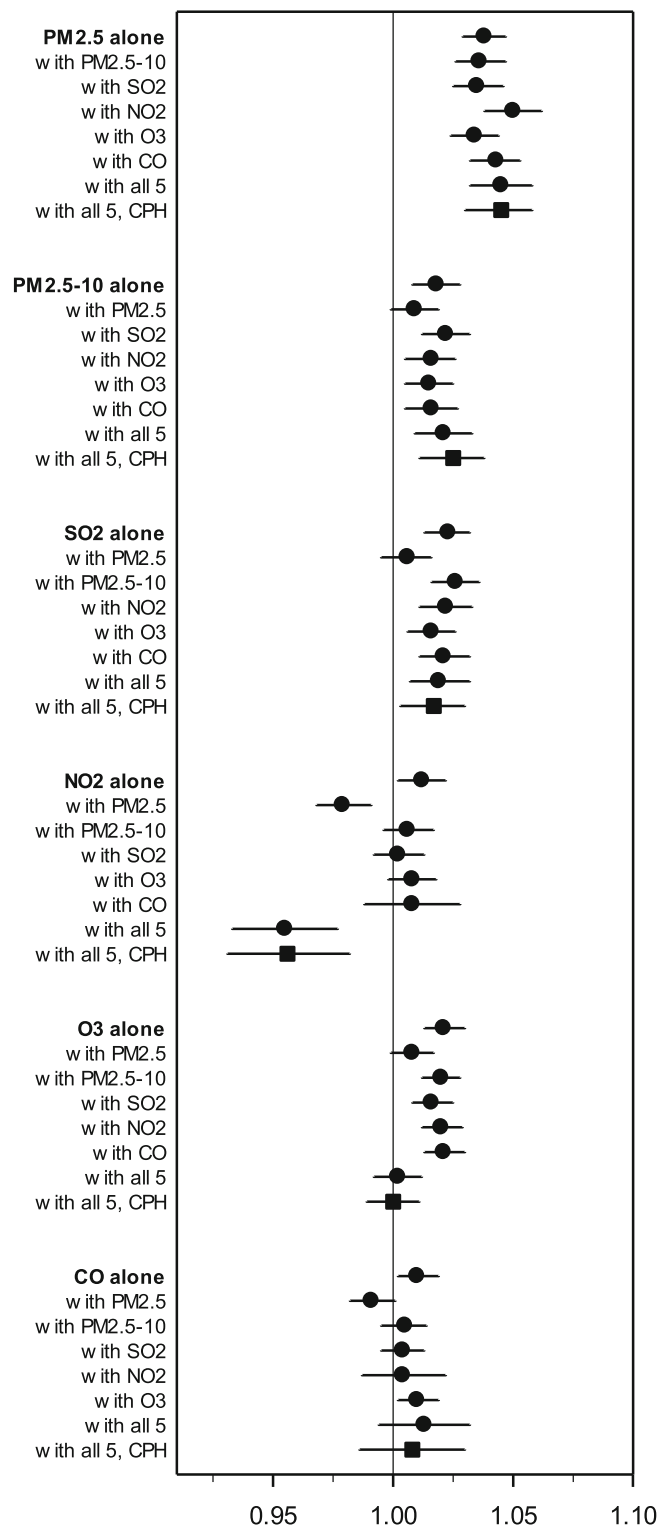

HR per IQR for all cause mortality

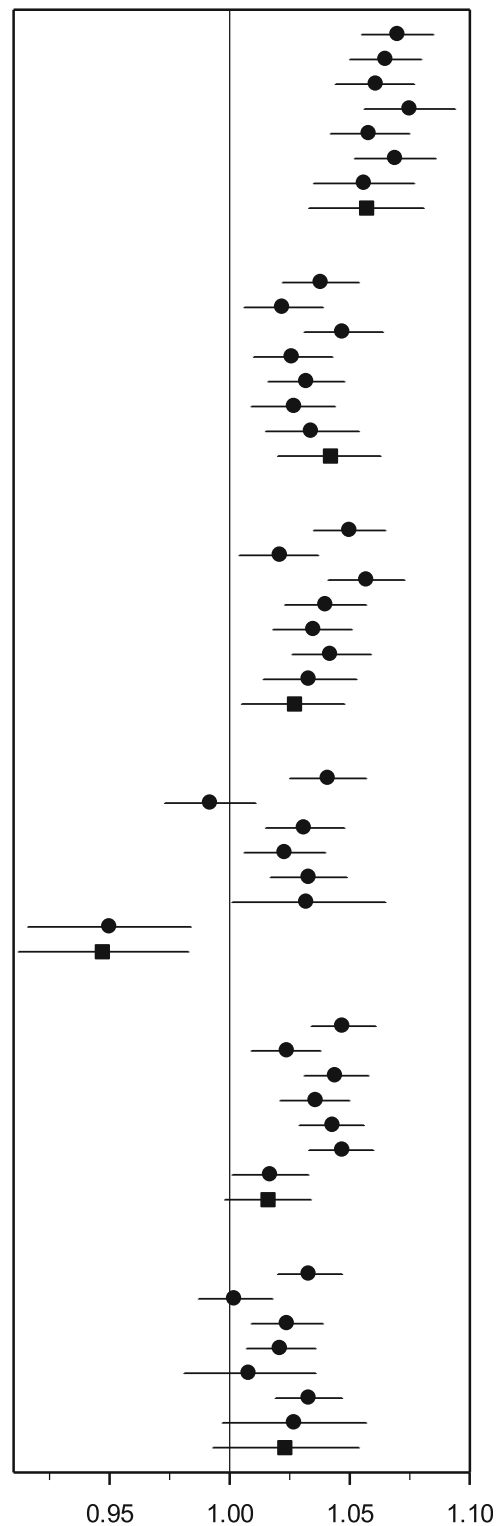

HR per IQR for cardiopulmonary mortality

Fig. 2 Illustration of regression results using 6 criteria pollutants, examining all-cause (left panel) and cardiopulmonary (right panel) mortality. Hazard ratios (and 95\% Cls) were estimated using models that adjusted for age, sex, race-ethnicity, marital status, inflation-adjusted household income, education, smoking status, BMI, U.S. Census region, urban versus rural designation, and survey year. Hazard ratios are represented with circles when estimated using basic proportional hazards regressions, and with squares when estimated using complex proportional hazards (PH) regressions. Data used to generate plot are listed in Additional file 1 Table S1.

local sources (industrial and road dust). As illustrated in Fig. 3, these results provide some evidence that local $\mathrm{PM}_{2.5}$ and neighborhood $\mathrm{PM}_{2.5}$ may be more strongly associated with mortality risk than regional $\mathrm{PM}_{2.5}$. Near-source $\mathrm{PM}_{2.5}$ was also more strongly associated with mortality risk than regional $\mathrm{PM}_{2.5}$ in another large U.S. cohort [32]. An implication of these results is that reliance on $\mathrm{PM}_{2.5}$-mortaltiy associations that are driven largely by regional differences in pollution may underestimate the health effects of exposure to local sources of pollution.

Strengths of the NHIS cohort have been described previously [25], which include the availability of detailed documentation, precise geographic information, large sample size, representativeness of U.S. adults, and individual-level controls for age, race-ethnicity, sex, smoking status, education, BMI, marital status, and income. Other strengths of this study include $a$ ) the robustness of the $\mathrm{PM}_{2.5}$-mortality 
Table 3 Correlations (Pearson's r) and summary statistics for spatial decompositions of PM $_{2.5}$ (2000-2015) in the NHIS cohort

\begin{tabular}{llccrrr}
\hline & $\begin{array}{l}\text { Local } \\
(<1 \mathrm{~km})\end{array}$ & $\begin{array}{l}\text { Neighborhood } \\
(1-10 \mathrm{~km})\end{array}$ & $\begin{array}{l}\text { Mid-range } \\
(10-100 \mathrm{~km})\end{array}$ & Regional $(>100 \mathrm{~km})$ & Mean & SD \\
\hline Local PM 2.5 & & & & 0.63 & 0.28 & 0.32 \\
Neighborhood PM $_{2.5}$ & 0.25 & & & 1.81 & 0.87 & 1.01 \\
Mid-range PM & & & & 2.59 & 1.45 & 1.53 \\
Regional PM $_{2.5}$ & 0.17 & 0.29 & -0.21 & 5.47 & 1.90 & 2.65 \\
\hline
\end{tabular}

Note: Local $\mathrm{PM}_{2.5}, \mathrm{PM}_{2.5}$ generated within $1 \mathrm{~km}$ of residence; neighborhood $\mathrm{PM}_{2.5}, \mathrm{PM}_{2.5}$ generated 1-10 km from residence; mid-range $\mathrm{PM}_{2.5}$, $\mathrm{PM}_{2.5}$ generated 10$100 \mathrm{~km}$ from residence; regional $\mathrm{PM}_{2.5}, \mathrm{PM}_{2.5}$ generated over $100 \mathrm{~km}$ from residence; SD, standard deviation; IQR, interquartile range

association in multiple-pollutant models that included modeled air pollution estimates for six criteria pollutants. $b$ ) The ability to examine the stability of other pollutant-mortality associations in multiple-pollutant models. $c$ ) The use of spatially-decomposed $\mathrm{PM}_{2.5}$ data to investigate whether the toxicity of $\mathrm{PM}_{2.5}$ depended on proximity to source. $d$ ) Temporally-decomposed analyses which allowed exposures and mortality effects to vary between years and facilitated comparisons of different windows of exposure.

This study also has important limitations. Like all observational studies, it was hindered by a lack of random exposure assignment, meaning it was susceptible to confounders that were unobserved or inadequately controlled for. Another limitation was the lack of follow-up for most individual-level data, including residential census tract, smoking status, marital status, and income. In multiplepollutant analyses, correlations among pollutants limit the ability to estimate independent associations between mortality risk and specific pollutants. For example, the correlation between $\mathrm{PM}_{2.5}$ and $\mathrm{NO}_{2}$ likely contributed to instability in the estimated effect of $\mathrm{NO}_{2}$ exposures; in models that controlled for $\mathrm{PM}_{2.5}, \mathrm{NO}_{2}$ was linked with

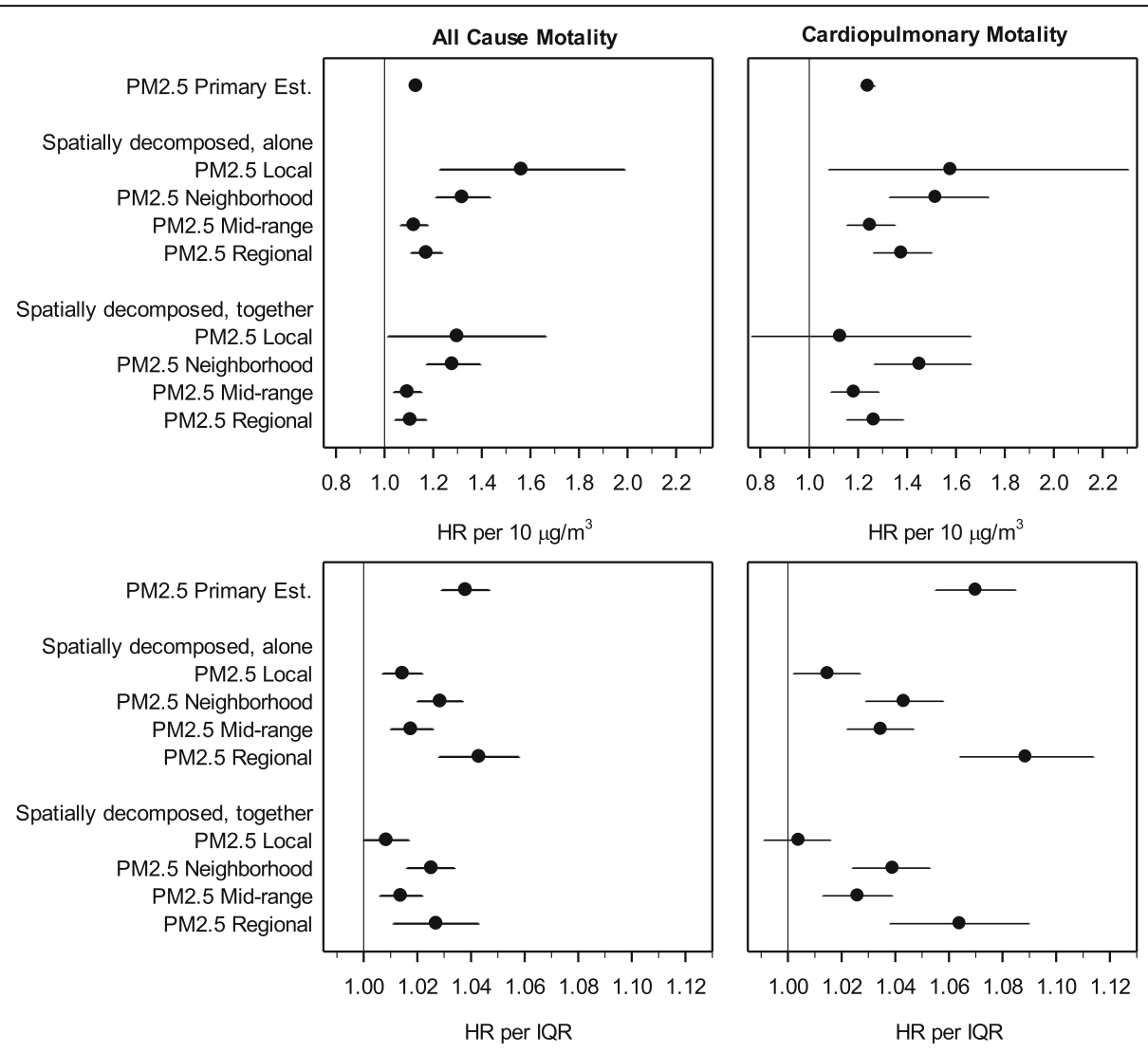

Fig. 3 Illustration of spatially-decomposed analyses, presented per $10 \mu \mathrm{g} / \mathrm{m}^{3}$ (top panel) and per IQR (bottom panel). Hazard ratios (and 95\% Cls) were estimated using the basic proportional hazards regressions model which adjusted for age, sex, race-ethnicity, marital status, inflationadjusted household income, education, smoking status, BMI, U.S. Census region, urban versus rural designation, and survey year. Local PM 2.5 , $\mathrm{PM}_{2.5}$ generated within $1 \mathrm{~km}$ of residence; neighborhood $\mathrm{PM}_{2.5}, \mathrm{PM}_{2.5}$ generated 1-10 km from residence; mid-range $\mathrm{PM}_{2.5}, \mathrm{PM}_{2.5}$ generated 10$100 \mathrm{~km}$ from residence; regional $\mathrm{PM}_{2.5}, \mathrm{PM}_{2.5}$ generated over $100 \mathrm{~km}$ from residence; IQR, interquartile range. Data used to generate plot are listed in Additional file 1 Table S2. 


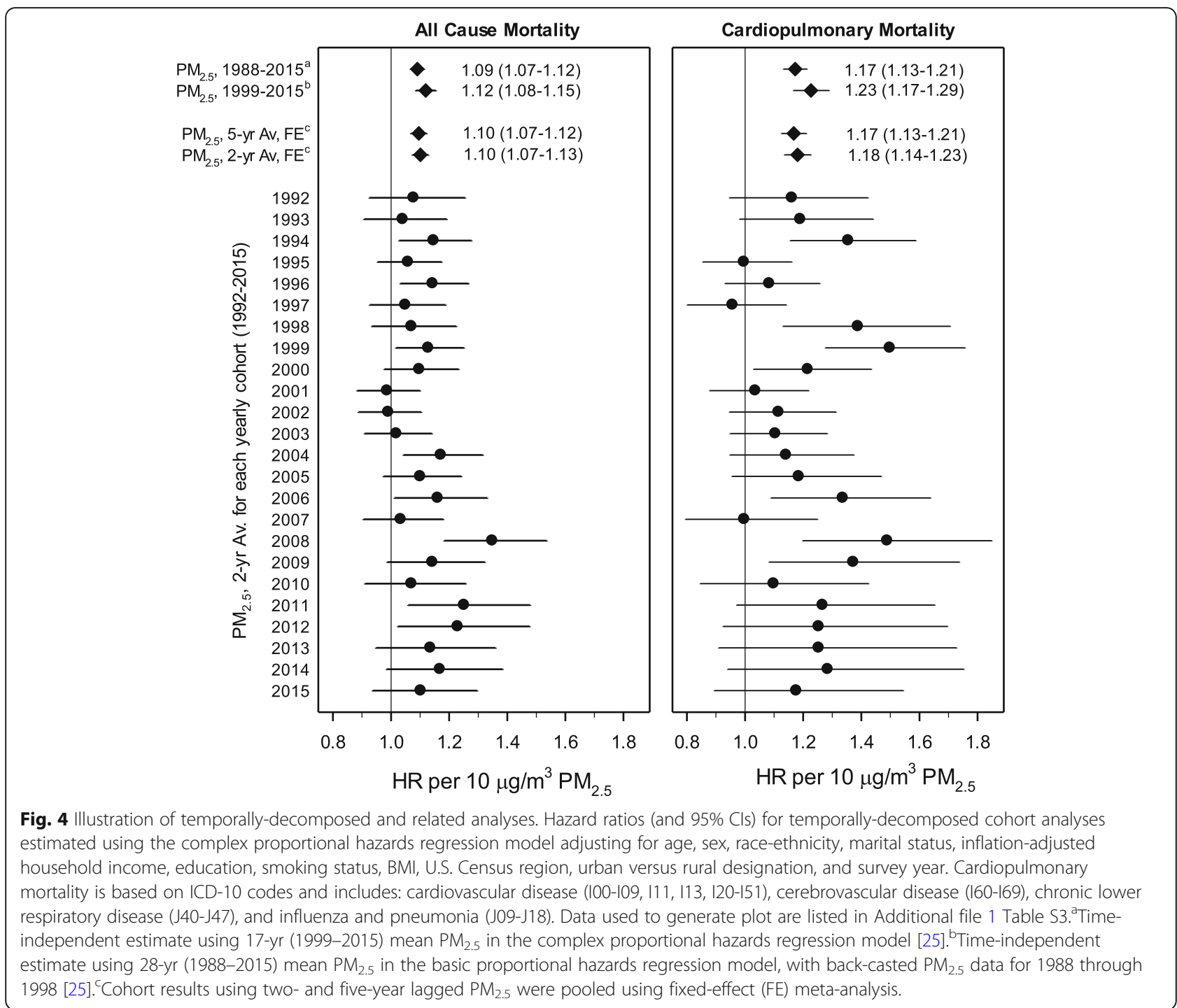

decreased mortality risk. Similarly, in the temporallydecomposed analyses, the correlation of $\mathrm{PM}_{2.5}$ exposures over time made it difficult to determine the most relevant exposure window. In addition, the lack of variation in $\mathrm{PM}_{2.5}$-mortality associations between years may reflect a lack of independence between yearly cohorts, in which case the standard errors from fixed-effect meta-analytic estimates may be underestimated.

\section{Conclusions}

Associations between long-term exposure to $\mathrm{PM}_{2.5}$ air pollution and mortality risk were robust to controlling for co-pollutants, observed across different spatial decompositions of $\mathrm{PM}_{2.5}$, and consistent over temporal decompositions of $\mathrm{PM}_{2.5}$. There was some evidence of increased toxicity for $\mathrm{PM}_{2.5}$ exposures that occurred closer to pollution sources. Exposures to $\mathrm{SO}_{2}$ and
$\mathrm{PM}_{2.5-10}$ were also linked to mortality risk, even when controlling for other air pollutants.

\section{Additional file}

Additional file 1: Table S1. Hazard ratios (and 95\% Cls) from regressions using 6 criteria pollutants, scaled by IQR. Table S2. Hazard ratios (and 95\% Cls) from spatially-decomposed analyses of $\mathrm{PM}_{2.5}$. Table S3. Hazard ratios (and 95\% Cls) from temporally-decomposed $\mathrm{PM}_{25}$ and related analyses. Figure S1. Illustration of the construction of temporally decomposed cohorts

\section{Acknowledgements}

Not applicable.

\section{Availability of data}

Air pollution data are available at www.caces.us/data. Public-use National Health Interview Survey data can be accessed at www.cdc.gov/nchs/ nhis/data-questonnaires-documentation.htm. For access to restricted-use geographic files, it is required to submit a proposal to the Research Data 
Center of the National Center of Health Statistics. Details are available at www.cdc.gov/rdc.

\section{Authors' contributions}

Conceptualization: CAP, RTB, ME, ALR, JDM; Data curation: JSL, JDH, JDM, MB, YW, ALR; Formal analysis: JSL, JDH, NCC, DDM, CAP; Methodology: JSL, RTB, $M E$, JDM, CAP; Supervision: CAP, ALR; Writing-original draft: JSL, CAP; Writing - review \& editing: All authors have read and approved the final manuscript.

\section{Authors' information}

Not applicable.

\section{Funding}

This publication was developed as part of the Center for Air, Climate, and Energy Solutions (CACES), which was supported under Assistance Agreement No. R835873 awarded by the U.S. Environmental Protection Agency. It has not been formally reviewed by EPA. The views expressed in this document are solely those of authors and do not necessarily reflect those of the Agency. EPA does not endorse any products or commercial services mentioned in this publication.

\section{Ethics approval and consent to participate}

Not applicable. The research reported in this manuscript uses public data that are de-identified and not subject to federal regulations on protection of human research subjects.

\section{Consent for publication}

Not applicable.

\section{Competing interests}

The authors declare they have no actual or potential competing financial interests.

\section{Author details}

${ }^{1}$ Department of Agricultural and Resource Economics, University of California, Berkeley, CA 94720, USA. ²Department of Economics, University of Chicago, Chicago, IL, USA. ${ }^{3}$ Health Canada, Ottawa, Ontario, Canada. ${ }^{4}$ MRC Centre for Environment and Health, School of Public Health, Imperial College London, London, UK. ${ }^{5}$ Department of Economics, Brigham Young University, Provo, UT, USA. ${ }^{6}$ Department of Civil and Environmental Engineering, University of Washington, Seattle, WA, USA. 'Engineering and Public Policy, Carnegie Mellon University, Pittsburgh, PA, USA.

Received: 26 August 2019 Accepted: 7 November 2019 Published online: 21 November 2019

\section{References}

1. Dockery DW, Pope CA, Xu X, Spengler JD, Ware JH, Fay ME, Ferris BG Jr, Speizer FE. An association between air pollution and mortality in six US cities. N Engl J Med. 1993;329(24):1753-9.

2. Pope CA III, Burnett RT, Thun MJ, Calle EE, Krewski D, Ito K, Thurston GD. Lung cancer, cardiopulmonary mortality, and long-term exposure to fine particulate air pollution. JAMA. 2002;287(9):1132-41.

3. Miller KA, Siscovick DS, Sheppard L, Shepherd K, Sullivan JH, Anderson GL, Kaufman JD. Long-term exposure to air pollution and incidence of cardiovascular events in women. N Engl J Med. 2007 Feb 1;356(5):447-58.

4. Jerrett M, Burnett RT, Pope CA III, Ito K, Thurston G, Krewski D, Shi Y, Calle E, Thun M. Long-term ozone exposure and mortality. N Engl J Med. 2009; 360(11):1085-95

5. Krewski D, Jerrett M, Burnett RT, Ma R, Hughes E, Shi Y, Turner MC, Pope CA III, Thurston G, Calle EE, Thun MJ. Extended follow-up and spatial analysis of the American Cancer Society study linking particulate air pollution and mortality. Health Effects Institute: Boston, MA; 2009

6. Lipsett MJ, Ostro BD, Reynolds P, Goldberg D, Hertz A, Jerrett M, Smith DF Garcia C, Chang ET, Bernstein L. Long-term exposure to air pollution and cardiorespiratory disease in the California teachers study cohort. Am J Respir Crit Care Med. 2011;184(7):828-35.

7. Puett RC, Hart JE, Suh H, Mittleman M, Laden F. Particulate matter exposures, mortality, and cardiovascular disease in the health professionals follow-up study. Environ Health Perspect. 2011;119(8):1130-5.
8. Lepeule J, Laden F, Dockery D, Schwartz J. Chronic exposure to fine particles and mortality: an extended follow-up of the Harvard six cities study from 1974 to 2009. Environ Health Perspect. 2012;120(7):965-70.

9. Carey IM, Atkinson RW, Kent AJ, Van Staa T, Cook DG, Anderson HR. Mortality associations with long-term exposure to outdoor air pollution in a national English cohort. Am J Respir Crit Care Med. 2013;187(11):1226-33.

10. Cesaroni G, Badaloni C, Gariazzo C, Stafoggia M, Sozzi R, Davoli M, Forastiere F. Long-term exposure to urban air pollution and mortality in a cohort of more than a million adults in Rome. Environ Health Perspect. 2013;121(3):324-31.

11. Beelen R, Raaschou-Nielsen $O$, Stafoggia M, Andersen ZJ, Weinmayr G, Hoffmann B, Wolf K, Samoli E, Fischer P, Nieuwenhuijsen M, Vineis P. Effects of long-term exposure to air pollution on natural-cause mortality: an analysis of 22 European cohorts within the multicentre ESCAPE project. Lancet. 2014;383(9919):785-95.

12. Bentayeb M, Wagner $V$, Stempfelet $M$, Zins M, Goldberg M, Pascal M, Larrieu S, Beaudeau P, Cassadou S, Eilstein D, Filleul L. Association between long-term exposure to air pollution and mortality in France: a 25-year follow-up study. Environ Int. 2015;85:5-14

13. Crouse DL, Peters PA, Hystad P, Brook JR, van Donkelaar A, Martin RV, Villeneuve PJ, Jerrett M, Goldberg MS, Pope CA III, Brauer M. Ambient PM 2.5 , $\mathrm{O}_{3}$, and $\mathrm{NO}_{2}$ exposures and associations with mortality over 16 years of follow-up in the Canadian census health and environment cohort (CanCHEC). Environ Health Perspect. 2015;123(11):1180-6.

14. Fischer PH, Marra M, Ameling CB, Hoek G, Beelen R, de Hoogh K, Breugelmans $\mathrm{O}$, Kruize $\mathrm{H}$, Janssen NA, Houthuijs D. Air pollution and mortality in seven million adults: the Dutch environmental longitudinal study (DUELS). Environ Health Perspect. 2015;123(7):697-704.

15. Hart JE, Liao X, Hong B, Puett RC, Yanosky JD, Suh H, Kioumourtzoglou MA, Spiegelman D, Laden $F$. The association of long-term exposure to $\mathrm{PM}_{2.5}$ on all-cause mortality in the Nurses' Health Study and the impact of measurement-error correction. Environ Health. 2015;14(1):38.

16. Thurston GD, Ahn J, Cromar KR, Shao Y, Reynolds HR, Jerrett M, Lim CC, Shanley R, Park Y, Hayes RB. Ambient particulate matter air pollution exposure and mortality in the NIH-AARP diet and health cohort. Environ Health Perspect. 2015;124(4):484-90.

17. Tseng $\mathrm{E}, \mathrm{Ho} W \mathrm{~W}$, Lin MH, Cheng TJ, Chen PC, Lin HH. Chronic exposure to particulate matter and risk of cardiovascular mortality: cohort study from Taiwan. BMC Public Health. 2015;15(1):936.

18. Villeneuve PJ, Weichenthal SA, Crouse D, Miller AB, To T, Martin RV, van Donkelaar A, Wall C, Burnett RT. Long-term exposure to fine particulate matter air pollution and mortality among Canadian women. Epidemiology. 2015:26(4):536-45

19. Pinault L, Tjepkema $M$, Crouse $D L$, Weichenthal $S$, van Donkelaar A, Martin RV, Brauer M, Chen H, Burnett RT. Risk estimates of mortality attributed to low concentrations of ambient fine particulate matter in the Canadian community health survey cohort. Environ Health. 2016;15(1):18.

20. Di Q, Wang Y, Zanobetti A, Wang Y, Koutrakis P, Choirat C, Dominici F, Schwartz JD. Air pollution and mortality in the Medicare population. N Engl J Med. 2017;376(26):2513-22.

21. Pinault LL, Weichenthal S, Crouse DL, Brauer M, Erickson A, van Donkelaar A, Martin RV, Hystad P, Chen H, Finès P, Brook JR. Associations between fine particulate matter and mortality in the 2001 Canadian census health and environment cohort. Environ Res. 2017:159:406-15.

22. Yin P, Brauer M, Cohen A, Burnett RT, Liu J, Liu Y, Liang R, Wang W, Qi J, Wang $L$, Zhou M. Long-term fine particulate matter exposure and nonaccidental and cause-specific mortality in a large national cohort of Chinese men. Environ Health Perspect. 2017;125(11):117002.

23. Parker JD, Kravets N, Vaidyanathan A. Particulate matter air pollution exposure and heart disease mortality risks by race and ethnicity in the United States: 1997 to 2009 national health interview survey with mortality follow-up through 2011. Circulation. 2018;137(16):1688-97.

24. Vodonos A, Awad YA, Schwartz J. The concentration-response between long-term PM2. 5 exposure and mortality; a meta-regression approach. Environ Res. 2018;166:677-89.

25. Pope CA III, Lefler JS, Ezzati M, Higbee JD, Marshall JD, Kim S-Y, Bechle M, Gilliat KS, Vernon SE, Robinson AL, Burnett RT. Mortality Risk and Fine Particulate Air Pollution in a Large, Representative Cohort of U.S. Adults. Environ Health Perspect. 2019. https://doi.org/10.1289/EHP4438.

26. Lenschow P, Abraham HJ, Kutzner K, Lutz M, Preuß JD, Reichenbächer W. Some ideas about the sources of PM10. Atmospheric Environ. 2001; $35: 523-33$. 
27. Bell ML, Dominici F, Ebisu K, Zeger SL, Samet JM. Spatial and temporal variation in PM2. 5 chemical composition in the United States for health effects studies. Environ Health Perspect. 2007;115(7):989-95.

28. National Center for Health Statistics. 2014 National Health Interview Survey: Survey Description. NCHS, Division of Health Interview Statistics. ftp://ftp. cdc.gov/pub/Health_Statistics/NCHS/Dataset_Documentation/NHIS/2014/ srvydesc.pdf (2015). Accessed 3 July 2019

29. National Center for Health Statistics (NCHS). NCHS data linked to NDI mortality files. https://www.cdc.gov/nchs/data-linkage/mortality.htm (2019). Accessed 3 July 2019.

30. Kim S-Y, Bechle M, Hankey S, Sheppard EA, Szpiro AA, Marshall JD. Concentrations of criteria pollutants in the contiguous U.S., 1979-2015: Role of model parsimony in integrated empirical geographic regression. UW Biostatistics Working Paper Series. Working Paper 425. https://biostats. bepress.com/uwbiostat/paper425.

31. Adar SD, Filigrana PA, Clements N, Peel JL. Ambient coarse particulate matter and human health: a systematic review and meta-analysis. Curr Environ Health Rep. 2014;1(3):258-74.

32. Turner MC, Jerrett M, Pope CA III, Krewski D, Gapstur SM, Diver WR, Beckerman BS, Marshall JD, Su J, Crouse DL, Burnett RT. Long-term ozone exposure and mortality in a large prospective study. Am J Respir Crit Care Med. 2016;192(10):1134-42.

\section{Publisher's Note}

Springer Nature remains neutral with regard to jurisdictional claims in published maps and institutional affiliations.

Ready to submit your research? Choose BMC and benefit from:

- fast, convenient online submission

- thorough peer review by experienced researchers in your field

- rapid publication on acceptance

- support for research data, including large and complex data types

- gold Open Access which fosters wider collaboration and increased citations

- maximum visibility for your research: over $100 \mathrm{M}$ website views per year

At $\mathrm{BMC}$, research is always in progress.

Learn more biomedcentral.com/submissions 